\title{
Intra-aortic balloon pump: is the tide turning?
}

\author{
Sandro Gelsomino ${ }^{1,2^{*}}$ (D), Daniel M. Johnson ${ }^{2,3}$ (D) and Roberto Lorusso ${ }^{1}$
}

Since the intra-aortic balloon pump (IABP) was used for the first time by Kantrowitz et al. [1] there has been controversy regarding its beneficial effects. In fact, even a report where Kantrowitz himself is senior author states [2]:

... Precise indications for initiation and termination of balloon counterpulsation remain in doubt.

However, after years of honest service, the IABP has been struck by a scientific thunderstorm called "SHOCK II", which has seriously questioned the use of this assist device in cardiogenic shock complicating acute myocardial infarction [3]. After the initial "SHOCK" of this trial there are still a number of questions remaining regarding the utility of the IABP, as well as a number of different "camps". There are both the "storm riders", who have always believed that the IABP had limited use, and, on the other side, the "honest IABP believers" who claim that successful use of IABP counterpulsation has been life-saving in many patients.

The majority of physicians, however, are in the middle, finding themselves "between a rock and hard place". These physicians are overwhelmed by the fear of not adhering to guidelines more than being really convinced of the lack of benefit of IABP use $[4,5]$. The net result of this "hurricane" is that, in clinical practice in Europe and the United States, the utilization rate of the IABP has been decreasing over the last few years (Fig. 1).

Remaining neutral between the opposing views and recognizing the unquestionable scientific value of the SHOCK II trial, doubt has been raised on whether our clinical convictions can be straightforwardly driven by evidence coming just from a single randomized trial.

A number of recent studies have shown that there is some sun on the horizon regarding use of the IABP. A

\footnotetext{
* Correspondence: sandro.gelsomino@maastrichtuniversity.nl

'Department of Cardiothoracic Surgery, Maastricht University Hospital, Maastricht, The Netherlands

${ }^{2}$ Department of Cardiothoracic Surgery, Cardiovascular Research Institute Maastricht_CARIM, Universiteitssingel 50, 6229 ER Maastricht, The Netherlands

Full list of author information is available at the end of the article
}

recent meta-analysis, for example, included 9212 patients and investigated the utility of the IABP when implanted preoperatively in patients undergoing coronary bypass graft surgery [6]. The results of this analysis strongly indicate that there is benefit in using the IABP under these conditions, with the relative risk reduction of mortality being more than $4 \%$. Furthermore, the risk of MI and renal failure were reduced when IABP treatment was instigated and both intensive care and total hospital stays were reduced, also indicating a possible economic benefit, as well as health benefit, of using the IABP [6].

Likewise, a recent study by Yang et al. [7], carried out in 416 patients with LV dysfunction undergoing off-pump coronary bypass grafting, showed that a preoperative IABP was linked with a lower 30-day mortality.

Interestingly, Iqbal et al. [8] recently carried out an observational analysis of 174 patients (with 55 patients receiving IABP) successfully resuscitated following an out-of-hospital cardiac arrest. In this study, the use of IABP therapy in the postresuscitation period was associated with improved functional recovery and outcomes, although the mortality rate was not different between the IABP and non-IABP groups [8].

Imamura et al. [9] recently showed that an elevation in central venous pressure and a lower heart rate were a predictor for significant hemodynamic response to IABP treatment in a population of decompensated heart failure patients. A very recent study [10] indicated that the IABP was associated with a lower risk of 30-day mortality in patients with acute myocardial infarction complicated by cardiogenic shock, in whom percutaneous coronary intervention was unsuccessful, whilst a higher risk of death was seen in patients where PCI had been successful. Taken together, these data indicate that improved patient selection may greatly influence outcomes.

Interestingly, use of the IABP together with other support systems, such as extracorporeal membrane oxygenation (ECMO), has also been receiving increased attention over recent years [11]. For example, a recent study by Meani et al. [12] showed the potential utility of the IABP to reverse aortic valve closure and impaired left ventricular 


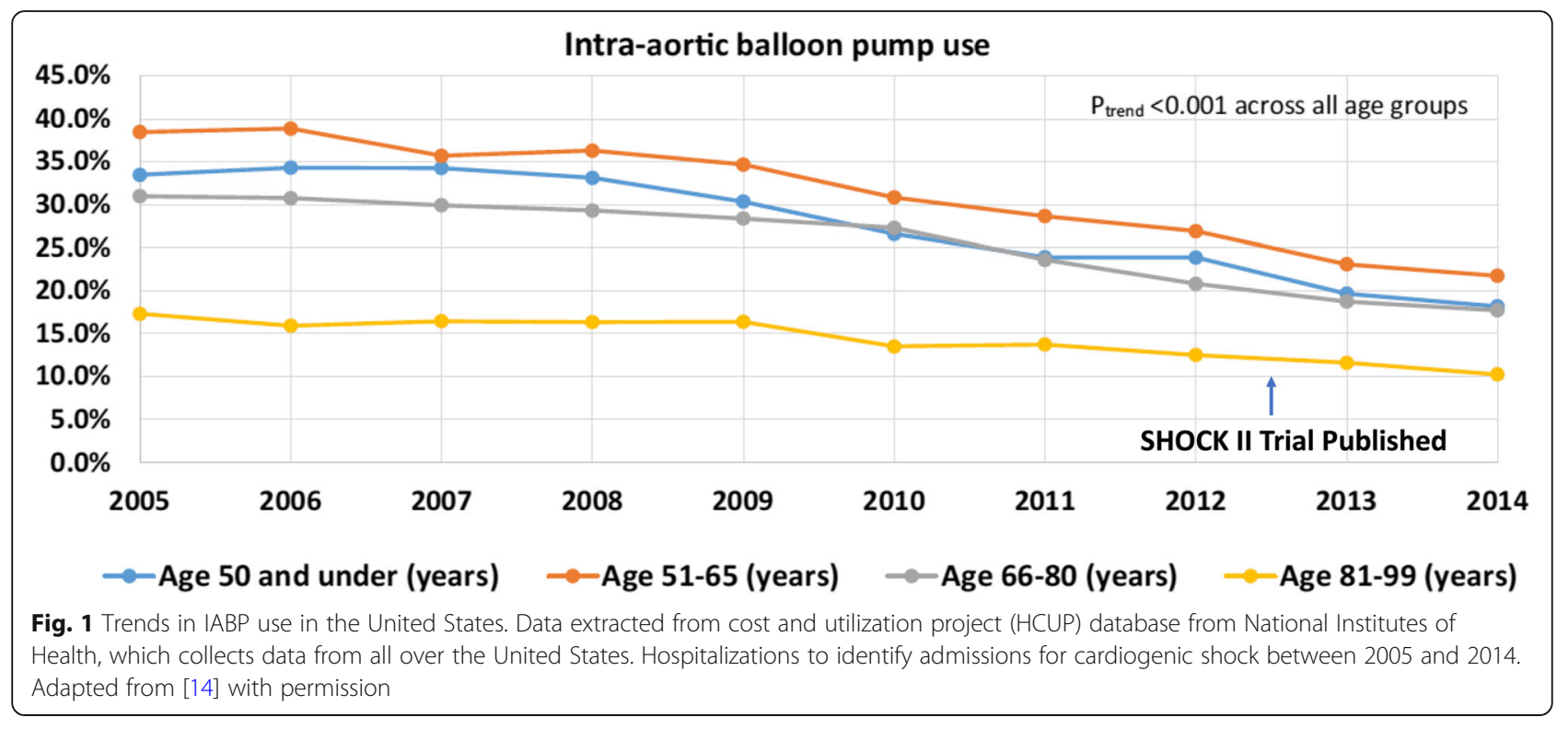

unloading that occurs during V-A ECMO support, whilst Bréchot et al. [13] showed that the association of IABP with V-A ECMO was associated with a lower frequency of pulmonary edema. Further research, both at the basic and the clinical level, is, however, required to fully understand the utility of such combination therapy.

Is the tide turning? At this stage, it is too early to say and we should be prudent, whilst at the same time critical, when examining studies. Nevertheless, the heavy debate on appropriate use of the IABP needs new lifeblood from numerous avenues including cardiologists, intensivists, anesthesiologists and cardiac surgeons. These specialties need to work together to actively contribute to a rigorous and objective data collection/examination/analysis. Furthermore, a key role needs to be played by companies involved in IABP development, who should, in our opinion, show an interest in gaining new scientific evidence to aid the scientific community in filling the considerable gap currently existing between guidelines and clinical practice.

In conclusion, maybe the time is right for new well-designed clinical trials to cause an "After-SHOCK II" in the field of IABP support. Only these data will properly inform the community whether there is some nice weather on the horizon or whether we just have a temporary rainbow.

\section{Abbreviation}

IABP: Intra-aortic balloon pump

\section{Acknowledgements}

Not applicable.

Funding

None to disclose.
Availability of data and materials Not applicable.

\section{Authors' contributions \\ All authors equally contributed to the manuscript. All authors read and approved the final manuscript.}

Ethics approval and consent to participate

Not applicable.

\section{Consent for publication}

All authors gave their final approval.

\section{Competing interests}

The authors declare that they have no competing interests.

\section{Publisher's Note}

Springer Nature remains neutral with regard to jurisdictional claims in published maps and institutional affiliations.

\section{Author details}

'Department of Cardiothoracic Surgery, Maastricht University Hospital, Maastricht, The Netherlands. ${ }^{2}$ Department of Cardiothoracic Surgery, Cardiovascular Research Institute Maastricht_CARIM, Universiteitssingel 50, 6229 ER Maastricht, The Netherlands. ${ }^{3}$ Institute of Cardiovascular Sciences, University of Birmingham, Birmingham, UK.

Received: 25 September 2018 Accepted: 18 November 2018 Published online: 18 December 2018

\section{References}

1. Kantrowitz A, Tjønneland S, Freed PS, Phillips SJ, Butner AN, Sherman JL. Initial clinical experience with intraaortic balloon pumping in cardiogenic shock. JAMA. 1968;203(2):113-8.

2. Scheidt $S$, Wilner $G$, Mueller H, Summers D, Lesch M, Wolff G, et al. Intraaortic balloon counterpoulsation in cardiogenic shock- report of a cooperative clinical trial. N Engl J Med. 1973;288:979-84

3. Thiele H, Zeymer U, Neumann F-J, Ferenc M, Olbrich H-G, Hausleiter J, et al. Intraaortic balloon support for myocardial infarction with cardiogenic shock. N Engl J Med. 2012;367(14):1287-96.

4. Ibanez B, James S, Agewall S, Antunes MJ, Bucciarelli-Ducci C, Bueno H, et al. 2017 ESC Guidelines for the management of acute myocardial infarction in patients presenting with ST-segment elevationThe Task Force for the management of acute myocardial infarction in patients presenting with ST- 
segment elevation of the European Society of Cardiology (ESC). Eur Heart J. 2018;39(2):119-77.

5. O'Gara PT, Kushner FG, Ascheim DD, Casey Jr DE, Chung MK, de Lemos JA, et al. 2013 ACCF/AHA Guideline for the management of ST-elevation myocardial infarction: a report of the American College of Cardiology Foundation/American Heart Association Task Force on Practice Guidelines. J Am Coll Cardiol. 2013;61(4):e78-140.

6. Deppe A-C, Weber C, Liakopoulos OJ, Zeriouh M, Slottosch I, Scherner M, et al. Preoperative intra-aortic balloon pump use in high-risk patients prior to coronary artery bypass graft surgery decreases the risk for morbidity and mortality —a meta-analysis of 9,212 patients. J Card Surg. 2017;32(3):177-85.

7. Yang F, Wang J, Hou D, Xing J, Liu F, Xing Z chen, et al. Preoperative intraaortic balloon pump improves the clinical outcomes of off-pump coronary artery bypass grafting in left ventricular dysfunction patients. Sci Rep. 2016; 6:27645.

8. Iqbal MB, Al-Hussaini A, Rosser G, Rajakulasingam R, Patel J, Elliott K, et al. Intra-aortic balloon pump counterpulsation in the post-resuscitation period is associated with improved functional outcomes in patients surviving an out-of-hospital cardiac arrest: insights from a dedicated heart attack centre. Heart Lung Circ. 2016;25(12):1210-7.

9. Imamura T, Juricek C, Nguyen A, Chung B, Rodgers D, Sayer G, et al. Predictors of hemodynamic improvement and stabilization following intraaortic balloon pump implantation in patients with advanced heart failure. J Invasive Cardiol. 2018;30(2):56-61.

10. Hawranek M, Gierlotka M, Pres D, Zembala M, Gąsior M. Nonroutine use of intra-aortic balloon pump in cardiogenic shock complicating myocardial infarction with successful and unsuccessful primary percutaneous coronary intervention. JACC Cardiovasc Interv. 2018;11(18):1885-93.

11. Li Y, Yan S, Gao S, Liu M, Lou S, Liu G, et al. Effect of an intra-aortic balloon pump with venoarterial extracorporeal membrane oxygenation on mortality of patients with cardiogenic shock: a systematic review and meta-analysis. Eur J Cardio-Thorac Surg Off J Eur Assoc Cardio-Thorac Surg. 2018.

12. Meani P, Delnoij T, Raffa GM, Morici N, Viola G, Sacco A, et al. Protracted aortic valve closure during peripheral veno-arterial extracorporeal life support: is intra-aortic balloon pump an effective solution? Perfusion. 2018 https://doi.org/10.1177/0267659118787426.

13. Bréchot N, Demondion P, Santi F, Lebreton G, Pham T, Dalakidis A, et al. Intra-aortic balloon pump protects against hydrostatic pulmonary oedema during peripheral venoarterial-extracorporeal membrane oxygenation. Eur Heart J Acute Cardiovasc Care. 2018 Feb;7(1):62-9.

14. Shah M, Patnaik S, Patel B, Ram P, Garg L, Agarwal M, et al. Trends in mechanical circulatory support use and hospital mortality among patients with acute myocardial infarction and non-infarction related cardiogenic shock in the United States. Clin Res Cardiol Off J Ger Card Soc. 2018;107(4): 287-303. 